\title{
ESTRATÉGIAS DE CRESCIMENTO DE COOPERATIVAS AGRÍCOLAS E AGROPECUÁRIAS: ESTUDO DE CASOS COMPARADOS DA REGIÃO DO TRIÂNGULO MINEIRO/MG E DOS CAMPOS GERAIS/PR
}

\author{
Growth Strategies of Agricultural Cooperatives: Comparative Case Studies of the \\ Triângulo Mineiro/MG and Campos Gerais/PR Regions
}

\begin{abstract}
RESUMO
Com este trabalho, de natureza qualitativa, buscou-se identificar as estratégias corporativas voltadas para o crescimento de cooperativas agrícolas e agropecuárias na região do Triângulo Mineiro, em Minas Gerais, e cooperativas agropecuárias na região dos Campos Gerais, no Paraná. Nessas regiões, o modelo cooperativista é difundido no ramo do agronegócio pelo reconhecimento dos produtores rurais de que esta é uma forma eficiente de organização, tornando-as relevantes no desenvolvimento econômico e social locais. Assim, foram pesquisadas doze cooperativas ao todo, por meio de entrevistas com seus gestores e pesquisa documental. Conclui-se que as cooperativas agrícolas e agropecuárias pesquisadas tiveram crescimento nos últimos cinco anos e que usaram com mais intensidade estratégias de crescimento interno com foco em integração vertical e, de forma mais esporádica, a aquisição também para fins de integração vertical. Elas estão iniciando estratégias de cooperação, sendo que as cooperativas da região dos Campos Gerais têm feito também a intercooperação. De acordo com a taxonomia de Miles e Snow (1978), foi possível observar que as nove cooperativas da região do Triângulo Mineiro apresentaram características da estratégia analítica, pois dependem e estão estruturadas com base em uma atividade ou cadeia produtiva principal, mais estável e com algumas unidades de negócios mais dinâmicas em que se permitem maiores riscos. Já as três cooperativas da região dos Campos Gerais apresentaram mais características da estratégia prospectora, onde a busca por novos mercados e produtos é intensa e leva-as à uma dinâmica de diversificação mais acelerada, sustentada pela estrutura e pela intercooperação.
\end{abstract}

Gustavo Moreira Borges

Universidade Federal de Uberlândia

moreiraborges@hotmail.com

Carlos Roberto Domingues

Universidade Federal de Uberlândia

carlosdomingues@yahoo.com.br

Recebido em: 17/05/2016. Aprovado em: 26/04/2017

Avaliado pelo sistema double blind review

Avaliador científico: Renato Silvério Campos

DOI: 10.21714/2238-68902017v19n1p008

\begin{abstract}
With this article of qualitative nature, we aimed to identify the corporate strategies for the growth of agribusiness cooperatives in the region of the Triângulo Mineiro (Minas Gerais State) and in the region of Campos Gerais (Paraná State). In these regions, the cooperative model is widespread in the field of agribusiness for rural producers who recognize the efficiency of this type of organization, which is relevant in local economic and social development. It was searched twelve cooperatives, through interviews with managers and documentary research. The findings showed that the agribusiness cooperatives have grown over the last five years and that they used more internal growth strategies with a focus on vertical integration rather than strategies of acquisition to vertical integration. They are initiating cooperation strategies, and some cooperatives in the region of Campos Gerais have made inter cooperation. According to the taxonomy of Miles and Snow (1978), it was possible to observe that the cooperatives in the region of the Triângulo Mineiro (nine) showed characteristics of analytical strategy because they depend and are structured based on one activity or a main production chain, which is more stable and have more dynamic business units, where they take more risks. The cooperatives in the region of Campos Gerais (three) were identified as presenting prospector strategy, where the search for new markets and products is intense and takes them to a dynamic diversification sustained by the their infrastructure and inter cooperation strategies.
\end{abstract}

Palavras-chave: Agronegócio, Modelo Cooperativista, Intercooperação, Taxonomia de Miles, Snow.

Keywords: Agribusiness, Cooperative Mode, Inter cooperation, Taxonomy of Miles, Snow.

\section{INTRODUÇÃO}

A cooperativa é um tipo especial de organização que consiste na união de indivíduos onde as necessidades profissionais de cada um, de comercialização ou a prestação de serviços em conjunto e os respectivos interesses sociais, políticos e econômicos visam aos propósitos coletivos da associação (CRÚZIO, 1999; BIALOSKORSKI NETO, 2013). De acordo com a Organização das Cooperativas do Estado de Minas Gerais - OCEMG (2014), as cooperativas são responsáveis por relevantes participações em seus ramos e produziram $7,2 \%$ do PIB do estado de 
Minas Gerais em 2013. No Paraná, a Organização das Cooperativas do Paraná - OCEPAR (2013) registrou uma participação das cooperativas de $13 \%$ da riqueza do estado, sendo o ramo agropecuário o mais presente.

O ramo do agronegócio contribuiu em $23 \%$ do PIB brasileiro em 2014, considerado uma importante fonte de crescimento da economia. Nas últimas duas décadas, o agronegócio se tornou um setor altamente competitivo, e com a exportação obteve expansão e internacionalização do capital nacional (HOPEWELL, 2014). As cooperativas agrícolas e agropecuárias são responsáveis por um relevante percentual do total produzido no setor do agronegócio. No Brasil, segundo a Organização das Cooperativas Brasileiras - OCB (2013), há 1.561 cooperativas agrícolas ou agropecuárias, que envolvem mais de um milhão de associados. Para Gimenes e Gimenes (2007), elas possuem o importante papel na melhoria e distribuição de renda da zona rural, principalmente no desenvolvimento local, devido aos seus princípios cooperativistas. Em Minas Gerais, de acordo a OCEMG (2014), as cooperativas agropecuárias estão em segundo lugar em movimentação econômica no estado. No Paraná, o ramo agropecuário é responsável por 55\% da economia agrícola do estado, lidera em número de cooperativas e empregados e situa-se em segundo lugar em número de cooperados (OCEPAR, 2013).

Identificou-se uma quantidade significativa de estudos sobre cooperativas agrícolas e agropecuárias, porém observou-se uma lacuna referente às estratégias de crescimento dessas organizações em revistas nacionais, como RAE, RAC e RAUSP, congressos no âmbito nacional, como EnANPAD e dissertações e teses das principais instituições de pós-graduação, ligados à área de Administração. Tais achados sugerem um distanciamento entre os estudos realizados a respeito deste ramo de atividade econômico importante e que, certamente, oferece contribuições para todas as áreas da Administração.

Assim sendo, o objetivo deste estudo foi identificar e analisar as estratégias de crescimento adotadas por cooperativas agrícolas e agropecuárias que estão situadas nas regiões do Triângulo Mineiro e Campos Gerais. Com isso, pretende-se contribuir para o conhecimento das estratégias deste tipo organizacional e a complexidade de seu ambiente.

\section{ESTRATÉGIAS COMPETITIVAS E CORPORATIVAS}

A literatura sobre estratégia faz uma distinção clara entre estratégias competitivas e estratégias corporativas, sendo que as primeiras estão relacionadas com o modo com que uma organização com um só tipo de negócio ou uma unidade de negócios de uma grande corporação compete em um setor de atividades particular. Já as estratégias corporativas são aquelas sobre as formas como a corporação gerencia o seu conjunto de negócios (BOWMAN; HELFAT, 2001; GHEMAWAT; RIVKIN, 2012). Logo, a estratégia corporativa é o plano geral de uma organização diversificada que trata das questões: de qual setor deve-se competir e como a sede corporativa gerencia as unidades de negócio. Para Hitt e Ireland (1996) e Kleinbaum e Stuart (2014), a estratégia corporativa é utilizada pelos executivos de altos níveis hierárquicos para direcionar a organização de forma geral. A essência da estratégia, para os autores, é a escolha por realizar atividades diversas ou executar as atividades de forma diferente, para possuir vantagem competitiva em cada um dos setores de atividades específicos. E a fim de conseguir competir em cada setor específico, recursos e competências são necessários.

Porter (2005) classifica a estratégia corporativa em quatro tipos: gestão do portfólio; reestruturação; transferência de atividades; e compartilhamento de atividades. A gestão de portfólio é a mais comum nas organizações e compreende a diversificação, por meio da criação ou aquisição de organizações com autonomia das unidades de negócio, em que é utilizada uma grande quantidade de informação e disposição para expandir ou se desfazer de negócios com baixo desempenho. A reestruturação é a reformulação de unidades de negócio ou setores subdesenvolvidos, de baixo desempenho ou ameaçados. A transferência de atividades consiste na estreita colaboração das unidades de negócios, ainda autônomas, com a alta administração. E por último, o compartilhamento de atividades, em que são aproveitados os benefícios do compartilhamento, que superam os custos, a utilização de novas empresas e aquisições como meio de entrar em novos mercados, onde a alta administração promove a integração das unidades de negócio. Os dois primeiros tipos de estratégia corporativa envolvem o ganho de valor por meio de cada unidade de negócio, em que o papel da corporação é visto como selecionador, banqueiro e interventor, já as duas últimas consistem na exploração da integração dos negócios (GHEMAWAT; RIVKIN, 2012).

Para Wright, Kroll e Parnell (2000), a estratégia corporativa pode ser classificada em: estratégias de crescimento, como resultado do aumento do faturamento ou participação de mercado, sempre em busca de um maior valor para a organização; estratégia de estabilidade, a qual 
foca na manutenção dos negócios, independente de qual for o motivo e por último as estratégias de redução, no intuito de eliminar negócios com retornos abaixo do esperado ou que podem ameaçar a continuidade da empresa. Estes movimentos vão depender dos recursos e competências que a organização possui, como consegue gerenciá-los e reconfigurá-los para aproveitar oportunidades ou evitar ameaças do seu ambiente externo (CHAKRABARTI; 2015).

Direcionada para o entendimento e classificação das estratégias competitivas, a taxonomia de Miles e Snow (1978) tornou-se uma forma interessante de analisar o comportamento individual das unidades de negócio e com isso compreender os posicionamentos individuais e as estratégias corporativas como um todo. $\mathrm{O}$ modelo foi classificado como uma tipologia estratégica, que consiste no conjunto de estratégias genéricas com capacidade de descrever os comportamentos estratégicos do setor de atividade. O modelo de Miles e Snow (1978) busca avaliar a adaptação organizacional, ocasionada pelas mudanças do ambiente, por meio da compreensão da relação entre estratégia, estrutura e processos. A adaptação da estratégia ao ambiente foi denominada de ciclo adaptativo, que deve ser visto como o modelo geral da fisiologia do comportamento organizacional, em que as etapas compreendem a solução para três tipos de problemas:

- Empresariais (entrepreneurial problem): domínio produto-mercado, postura de sucesso, monitoração do ambiente e política de crescimento;

- Tecnológicos ou de produção (engineering problem): objetivos tecnológicos, amplitude tecnológica e orientação tecnológica;

- Administrativos ou estruturais (administrative problem): função administrativa dominante, atitude de planejamento, estrutura organizacional e controle.

O desempenho da organização depende do alinhamento das soluções adotadas para os três tipos de problemas que devem ser resolvidos pela empresa. $\mathrm{O}$ modelo proposto classifica as organizações ou unidades de negócio em quatro categorias estratégicas adaptativas distintas, que são: defensiva, prospectora, analítica e reativa (MILES; SNOW, 1978).

As estratégias prospectoras e defensivas são contrastantes e opostas, sendo que a estratégia prospectiva é caracterizada pela busca de novos mercados e inovação de produtos e processos, as organizações possuem uma posição competitiva agressiva, geralmente elas são pioneiras e o risco da estratégia é alto, já as defensivas possuem um estreito domínio de produtos ou mercados, em busca de eficiência, não se preocupam com novas oportunidades, mas sim em manter preços competitivos ou qualidade do produto. As estratégias analíticas são híbridas entre as prospectoras e defensivas, que se caracterizam por possuir uma área de negócio central mais estável, e componentes dos negócios que são mais dinâmicos, entendida como prospectora (GIMENEZ et al., 1999). A estratégia reativa é considerada por Miles e Snow (1978) como aquela que não apresenta nenhuma relação entre estratégia e estrutura ou mecanismos e processos para se adaptar ao mercado, podendo ser chamada de não estratégia, em que a organização é forçada por pressões competitivas à mudança (GIMENEZ et al., 1999).

De acordo com Vieira et al (2012, p. 74-75), esta taxonomia tem chamado a atenção de pesquisadores da área de administração, pois ela especifica os "relacionamentos entre estratégia, estrutura e processos de uma forma que permite a identificação das organizações como universos integrados em interação com seus ambientes". E estes ambientes são compostos por i) o ambiente em si composto por ações organizacionais; ii) as escolhas estratégicas que definem a estrutura e os processos organizacionais; e iii) os processos e estrutura que condicionam a estratégia.

Deve-se considerar que há críticas quanto ao uso da tipologia de Miles e Snow (1978), na sua forma original. Uma delas é o seu alcance de explicação nos dias atuais, visto que foi desenvolvida a partir dos anos de 1970. Outras críticas mais pontuais são elaboradas pelos autores: i) Zajac e Shortell (1989) que consideram a questão do número de segmentos e as capacidades estudadas das organizações limitadas, o que complica a condição de descrever de forma empírica se uma perspectiva superaria a outra e em quais circunstâncias; ii) Gimenez (1998) que faz uso de uma combinação de Miles e Snow (1978) com uma de Kiston (1976) com a finalidade de investigar as estruturas cognitivas adotadas pelos gestores de pequenas empresas afirma que estas afetam e levam à diferenciação das estratégias, estrutura, tecnologia e administração; iii) DeSarbo et al (2005) indicam que as tipologias de Miles e Snow (1978) deixam de medir o real perfil da organização, mas medem o perfil atual e de determinado momento o que não refletiria o perfil da organização.

E, finalmente, por ser um modelo genérico houve autores que realizaram o seu desdobramento por meio da mesclagem com outras teorias, como em: Zajac e Shortell (1989); Gimenez (1998); DeSarbo et al. (2005) e Lopes, Moura e Oliveira (2010), a fim de analisar aspectos específicos de determinadas realidades. Entretanto, este 
movimento tem sido pontual e preserva os elementos básicos do modelo.

A pesquisa de Vieira et al (2012) realizada entre os anos 1997 e 2010, nos principais congressos em gestão do Brasil, identificou que as pesquisas encontradas estavam restritas aos setores/tipos de negócio: Hotelaria; Plásticos; Lojas Varejistas; Fast Food; Construtoras; Franquias; e Empresas de Pequeno Porte, dentre outras. E, por meio de uma análise mais ampla nas bases de dados do SPELL e Periódicos Capes foram identificados dois artigos que envolviam o agronegócio, nenhuma pesquisa que contemplasse as cooperativas do ramo do agronegócio em que fosse utilizando a tipologia de Miles e Snow (1978).

Mesmo considerando os aspectos limitadores, as críticas e as possibilidades de ampliação do modelo, decidiu-se por realizar esta pesquisa utilizando o modelo com os seus elementos originais, pois constatou-se o fato de que as cooperativas agropecuárias não foram ainda analisadas usando-se esta tipologia. Além disso, uma das vantagens da aplicação do modelo é contornar a questão do porte das empresas pesquisadas com faturamentos distintos, e ainda, por ser um modelo que privilegia a análise das estratégias adotadas pelas empresas e a sua interação com o ambiente competitivo, neste caso, permitindo a análise das cooperativas no ambiente competitivo do agronegócio. Destaca-se ainda, que este modelo tem sido amplamente utilizado em pesquisas recentes da área de Administração como, por exemplo, Bahls et al (2014), Gallas et al (2015) e Anacleto (2016).

\section{ESTRATÉGIAS DE CRESCIMENTO}

Wright, Kroll e Parnell (2000) e Barney e Hesterly (2007) descrevem as principais estratégias corporativas de crescimento como: crescimento interno, integração horizontal, diversificação horizontal relacionada e não relacionada, integração vertical de empresas relacionadas e não relacionadas, fusões e alianças estratégicas. $\mathrm{O}$ crescimento interno é obtido com o aumento das vendas, capacidade de produção e força de trabalho. Quem defende a estratégia alega possuir vantagem ao preservar melhor a cultura organizacional, eficiência, qualidade e imagem. $\mathrm{O}$ crescimento interno pode ser com aumento do próprio negócio ou com a inserção em novos setores e atividades. O crescimento interno horizontal envolve a criação de novas empresas relacionadas ou não, já o crescimento interno vertical é a criação de negócios relacionados ou não envolvendo a relação de fornecedor cliente no canal de distribuição da empresa.
Para Wright, Kroll e Parnell (2000), a integração horizontal nada mais é do que a aquisição de empresas da mesma linha de negócio. Geralmente os motivos são o aumento da receita e maior participação do mercado, o que leva a um maior poder de negociação com fornecedores e clientes, economia de escala e gera maior flexibilidade operacional. Barney e Hesterly (2007) acrescentam que a integração horizontal proporciona o aumento do poder de mercado da organização, por meio das sinergias baseadas em custos e receitas. Logo, percebe-se que a ação deve ser de aquisição, pois representa que uma empresa está crescendo, e não efetuando processos de fusão.

A diversificação horizontal consiste na aquisição de uma ou mais empresas de outro setor, podendo ser relacionadas ou não. $\mathrm{Na}$ diversificação horizontal relacionada, a aquisição está associada com as competências essenciais da organização, que podem ser semelhantes ou complementares. As vantagens da diversificação horizontal relacionada são: economia de escopo horizontal, inovações de escopo horizontal e a combinação entre as duas (WRIGHT; KROLL; PARNELL, 2000; GHEMAWAT; RIVKIN, 2012). A diversificação relacionada é adotada para utilizar ou ampliar os recursos, capacidades e competências essenciais para a criação de valor, com o intuito de desenvolver e explorar economias de esfera de ação entre suas unidades de negócio (BARNEY; HESTERLY, 2007).

Wright, Kroll e Parnell (2000) e Hoskisson, Hitt, Ireland e Harrisson (2010) ratificam que, ao contrário da última, quando a organização adquire outra empresa de setor não relacionada, a empresa executa uma diversificação horizontal não relacionada ou diversificação por conglomerados. De acordo com os autores, diferente da relacionada, a diversificação por conglomerados é executada principalmente por motivos de investimento financeiro, e também com o intuito de diversificação, com a redução do risco.

A integração vertical consiste em unir vários estágios de atividades regressivamente, tanto na direção dos suprimentos, quanto ao consumidor final, ela pode ser plena ou parcial. Assim, entende-se o uso da estratégia quando a organização está presente em mais de um estágio da cadeia produtiva (WRIGHT; KROLL; PARNELL, 2000; BRITTO, 2002). Britto (2002) afirma que os motivos de uma organização utilizar a estratégia de integração vertical são devidos aos custos de transação, ordem técnica, eficiência econômica e competição. A integração vertical se distingue em empresas relacionadas, que é a aquisição de empresas com competências essenciais semelhantes 
ou complementares e integração vertical de empresas não relacionadas, como a aquisição de empresas que possuem probabilidades limitadas de transferência ou partilha de competências essenciais. Segundo Barney e Hesterly (2007), a integração vertical é utilizada principalmente na atividade principal da empresa, com o objetivo de se obter poder de mercado em relação aos rivais.

Para Wright, Kroll e Parnell (2000), a fusão é uma estratégia de crescimento em que duas ou mais empresas, de tamanhos praticamente iguais, se unem por permuta de ações, podendo ser horizontal ou vertical. A principal razão pela qual é realizada a estratégia é para ganhar força competitiva. As fusões acarretam grandes custos, então é necessário fazer um planejamento acurado para que os benefícios excedam os custos. Já para Ross, Westerfield e Jaffe (2002) a fusão consiste em uma empresa absorver outra, em que normalmente a organização que absorveu, conserva o seu nome e identidade, e todos os ativos e passivos são incorporados por ela. Barney e Hesterly (2007) afirmam que a fusão deve ser adotada quando a organização adquirente agregar maior valor econômico através do controle acionário e do uso dos ativos da empresa adquirida. A fusão pelos autores consiste numa estratégia em que duas empresas aceitam integrar suas operações em base relativamente igual. Os motivos pelos quais as empresas resolvem utilizar a estratégia são: aumento do poder de mercado, superação das barreiras à entrada, redução de custos e riscos associados ao desenvolvimento de novos produtos e maior rapidez para lançamento no mercado, a transferência de know how e o efeito da tributação.

Para Aaker (2001) a aliança estratégica consiste na união de esforços de organizações com a finalidade de alcançar um objetivo estratégico comum. Wright, Kroll e Parnell (2000) definem aliança estratégica na formação de parcerias para que duas ou mais empresas realizem projetos específicos ou cooperem em determinadas áreas de negócio. O prazo pode ser curto ou longo e os motivos para a formação podem ser diversos, como político, econômico ou tecnológico. Os participantes dividem os riscos, custos e os benefícios de adentrarem em outros negócios.

Para Barney e Hesterly (2007), as alianças estratégicas são vistas como a principal forma de estratégia corporativa, em que se permite que as empresas combinem recursos e capacidades para criar vantagem competitiva. Arruda e Arruda (1997) afirmam que os motivos para se utilizar a aliança estratégica são: a complexidade da atividade que tange a estratégia, acesso de recursos e competências do parceiro, acesso a mercados de produtos e geográficos, conhecimento sobre mercados, matéria-prima, infraestrutura de marketing, marcas reconhecidas, clientes importantes, superação de barreira e restrições, acesso ao capital de crédito de curto e longo prazos.

\section{COOPERATIVAS AGRÍCOLAS E AGROPECUÁRIAS}

De acordo com Bialoskorski Neto (2013), os primeiros movimentos cooperativistas modernos aconteceram de forma sólida na Inglaterra em 1844 em Rochdale, próximo a Manchester, com a criação de uma cooperativa de consumo, composta principalmente por tecelões, com a intenção de melhorar a precária situação econômica pelo auxílio mútuo. A expansão do cooperativismo se fez com a disseminação dos ideais cooperativistas por meio de organizações mundiais como a International Cooperative Alliance.

Crúzio (1999) define a cooperativa como a união de pessoas em que os interesses individuais de trabalho são congruentes com os interesses coletivos da associação. $\mathrm{O}$ autor salienta ainda que a principal diferença entre outro tipo de organização para a cooperativa é que cada sócio possui direito a um voto, não dependendo da influência sobre o capital individual. Porém, externamente a cooperativa possui a semelhança pela busca do lucro, desse modo se iguala na forma de concorrência com o mercado. Em referência a um estudo da Aliança Cooperativa Internacional mostra-se que o sistema de cooperativa está presente em 100 países, e geram mais de 100 milhões de empregos. No Brasil, de acordo com a OCB (2013), referente a dados de 2013, há mais de 11 milhões de brasileiros que participam do cooperativismo, sendo que 5,2 milhões estão agrupados em cooperativas e o agronegócio consiste em um dos principais ramos de cooperativas no Brasil, totalizam-se 1.561 cooperativas agropecuárias, que possuem mais de 1 milhão de cooperados em todo o país, com 155.896 empregos diretos. No ano de 2010 as cooperativas agropecuárias exportaram 6,1 bilhões de dólares. Segundo Gimenes e Gimenes (2007), as cooperativas do agronegócio possuem papel relevante na melhoria da distribuição de renda da zona rural, visto que as associações podem agregar valor aos produtos resultantes do setor e expressar um maior poder em mercados relativamente imperfeitos.

$\mathrm{O}$ agronegócio consiste num sistema empresarial, em que estão presentes todos os agentes produtores para o mercado ou desenvolvimento de qualquer empreendimento 
com vista à maximização do lucro, no plano do sistema agroalimentar. $\mathrm{Na}$ condição atual do agronegócio, anterior (à montante) ao setor produtivo localizam-se os componentes de suprimento e apoio (fornecedores de insumo, máquinas e equipamentos) e aportes de fatores tradicionais de produção (capital e mão-de-obra). Posterior ao setor produtivo (à jusante) situam-se as organizações responsáveis pelo processamento e as redes de distribuição, representadas pelos atacadistas e varejistas. Por último os consumidores, como componente final e agentes ativos do sistema agroalimentar. Os autores mostram que, inicialmente, o poder do agronegócio se estabelecia no campo após a segunda guerra mundial, com o avanço da tecnologia e a busca de maior eficiência o poder se transferiu para a indústria e atualmente, em seu terceiro momento o poder passou para o segmento de distribuição, em que os consumidores passaram a representar os agentes consumidores ativos no processo através do avanço das tecnologias de comunicação e de marketing (VILELA; MACEDO, 2000; BATALHA; SILVA, 2013).

As cooperativas constituem em importante agente no agronegócio brasileiro, sendo formadas por produtores rurais que necessitam de uma estrutura de apoio à produção, auxílio para obtenção de crédito agrícola, estruturas de armazenagem, comercialização e industrialização da produção (BIALOSKORSKI NETO, 2013; CRÚZIO, 1999). O principal ganho do modelo cooperativo é elevar a renda do associado, e a explicação é devido à estrutura mesoeconômica de agregação de economias particulares, o que permite o ganho com as transações ao longo da cadeia agroalimentar, gerando uma maior facilidade na negociação do produtor com as estruturas de mercado oligopolizadas, à montante e à jusante da etapa de produção e permite uma economia de escala para o cooperado. Porém, a cooperativa em sua estrutura organizacional possui dificuldades, como a tendência da maximização do ganho isolado do produtor e não da cooperativa, em que a própria doutrina do cooperativismo em relação à inexistência do lucro favorece essa situação (BIALOSKORSKI NETO, 2013).

Cabe destacar a intercooperação entre as cooperativas, desde contratos relacionais entre firmas e organizações, influenciadas por vários fatores econômicos, como escala e tamanho, a necessidade de redução de custos e transação e de riscos envolvidos nos mercados (BIALOSKORSKI NETO, 2010). Pode-se aplicar a intercooperação em vários estágios que vão de menos a mais complexos. Inicialmente é utilizada uma rede relacional e informal, gestora de contratos informais e relacionais entre cooperativas. Um segundo estágio compete a um sistema de compensação de contratos entre as cooperativas, que pode ser criada uma organização formal e não cooperativa, com a função de gerir contratos e informações, promovendo maior força de barganha, como na compra de suprimentos, frequentemente consórcios. $\mathrm{O}$ próximo estágio é a existência de estruturas coordenadoras como "joint-venture", "holding" ou cooperativa central, que consiste de uma nova empresa, que é responsável pela gestão de parte de processos e produtos, e que é controlada pelas cooperativas participantes. E por último, muito comum no Brasil, a incorporação de uma cooperativa por outra, ou uma prática menos usual e complexa que é a fusão entre as cooperativas, criando uma nova organização (BARROSO et al., 2007).

\section{PROCEDIMENTOS METODOLÓGICOS}

Esta pesquisa teve abordagem qualitativa, do tipo descritiva por meio da estratégia de estudo de casos comparados. De acordo com Yin (2015), este tipo de estudo consiste na análise de cada caso e, posterior análise entre os casos chamada de cross-case. A coleta de dados foi feita por meio de entrevistas com gestores de cooperativas para identificação das estratégias adotadas, especificamente as estratégias de crescimento e posterior análise comparativa. A partir da indicação dos respondentes quanto às formas de acesso e quais os conteúdos disponíveis, foi realizada uma pesquisa documental nos dados dos relatórios da OCEPAR e da OCEMG, além de informações contidas nos sites institucionais das cooperativas a fim de caracterizar e analisar cada cooperativa no que diz respeito às suas respectivas histórias, estrutura organizacional, unidades de negócios e volume de produção.

O critério de escolha das cooperativas pesquisadas foi diferente nas duas regiões. Em Minas Gerais, analisouse previamente os relatórios anuais da OCEMG, onde foram identificadas cooperativas agrícolas e agropecuárias instaladas na região do Triângulo Mineiro. Por meio dos indicadores financeiros usados como critérios (ativos totais, capital social, patrimônio líquido, receita, salário médio dos empregados e sobra média por associado), foram escolhidas as maiores cooperativas do agronegócio da região. Assim, do total de 41 cooperativas foram escolhidas 11 para participar do estudo. No caso das cooperativas agropecuárias do Paraná, identificou-se por meio de informações obtidas junto à OCEPAR que a região dos Campos Gerais é uma das mais importantes e pioneira no cooperativismo agropecuário no estado. Assim, foram 
identificadas 3 cooperativas agropecuárias na região que foram selecionadas para esta pesquisa.

Das cooperativas de Minas Gerais selecionadas, apenas duas não responderam a entrevista, assim, foram 9 as cooperativas mineiras estudadas. Os gestores das 3 cooperativas do Paraná aceitaram participar da pesquisa e as entrevistas foram realizadas no mês de novembro de 2015. O Quadro 1 apresenta um breve histórico de cada cooperativa com os dados que foram coletados nos respectivos sites e como pode-se observar, alguns dados, como resultado financeiro, número de associados, não foram divulgados por todas as cooperativas, o que não maculou a pesquisa. Para fins deste trabalho, as empresas tiveram seus nomes alterados por nomes de aeronaves.

QUADRO 1 - Apresentação das Cooperativas Estudadas

\begin{tabular}{|c|c|c|}
\hline EMPRESA & REGIÃO & DESCRIÇÃO \\
\hline Seneca & $\begin{array}{l}\text { Triângulo } \\
\text { Mineiro }\end{array}$ & $\begin{array}{l}\text { Iniciou suas atividades em 1958. Atualmente possui o objetivo de profissionalizar o produtor. É filiada } \\
\text { com uma cooperativa central de leite, possui unidades de negócio de milho, café, fábrica de ração e } \\
\text { lojas comerciais. }\end{array}$ \\
\hline Saratoga & $\begin{array}{l}\text { sulo } \\
\text { iro }\end{array}$ & $\begin{array}{l}\text { Fundada em 1966, possui armazém de grãos, silo de milho, fábrica de ração e de suplemento natural, } \\
\text { cinco lojas comerciais e prestação de serviço ao cooperado. Em 2014, registrou } 5.293 \text { associados. }\end{array}$ \\
\hline Matrix & $\begin{array}{l}\text { Triângulo } \\
\text { Mineiro }\end{array}$ & $\begin{array}{l}\text { Iniciou suas atividades no ano de } 1961 \text {, com o intuito de fornecer insumos aos cooperados. Desde } \\
\text { sua fundação, a organização foi incorporando novas unidades de negócios, na década de } 90 \text { se filiou } \\
\text { a uma cooperativa central. Atualmente trabalha com industrialização de derivados do leite, armazém } \\
\text { graneleiro, prestação de serviços aos cooperados, fábrica de ração, supermercado, planos de saúde e } \\
\text { postos de combustíveis. Em 2014, registrou } 3.044 \text { associados e } 350 \text { milhões de faturamento }\end{array}$ \\
\hline Cherokee & $\begin{array}{l}\text { Triângulo } \\
\text { Mineiro }\end{array}$ & $\begin{array}{l}\text { A cooperativa iniciou sua operação no ano de 1994. A empresa trabalha com diversas culturas, entre } \\
\text { elas café, milho, soja e trigo, possui uma indústria de beneficiamento de semente, comercializa } \\
\text { produtos como sementes, insumo e produtos agrícolas. Em 2014, faturou } 308 \text { milhões de reais. }\end{array}$ \\
\hline Meridian & $\begin{array}{l}\text { Triângulo } \\
\text { Mineiro }\end{array}$ & $\begin{array}{l}\text { Foi criada em 1957, trabalha principalmente com o leite produzido pelos cooperados, no } \\
\text { beneficiamento, industrialização e comercialização, com o fornecimento de insumos, bens de } \\
\text { consumo e equipamentos, serviços de assistência ao cooperado e postos de combustíveis. Em 2014, } \\
\text { possuía } 1.862 \text { associados e faturou aproximadamente } 224 \text { milhões de reais. }\end{array}$ \\
\hline Jetprop & $\begin{array}{l}\text { igulo } \\
\text { eiro }\end{array}$ & Cooperativa agropecuária que trabalha principalmente com cana-de-açúcar e seus derivados. \\
\hline Tupi & $\begin{array}{l}\text { Triângulo } \\
\text { Mineiro }\end{array}$ & $\begin{array}{c}\text { Fundada em 1965, iniciou suas atividades no ramo leiteiro. Atualmente, a produção de leite foi } \\
\text { expandida e a cooperativa se filiou a uma cooperativa central, ampliou seus negócios para grãos, } \\
\text { supermercado, nutrição animal, assistência ao associado e indústrias de produção de derivados de } \\
\text { leite. Em 2014, faturou } 223 \text { milhões de reais. }\end{array}$ \\
\hline Corisco & $\begin{array}{l}\text { Triângulo } \\
\text { Mineiro }\end{array}$ & $\begin{array}{r}\text { Cooperativa recente, criada em 2002, com a união de produtores de leit } \\
\text { de resfriamento, fábrica de ração e sal mineral e lojas }\end{array}$ \\
\hline Navajo & $\begin{array}{l}\text { Triângulo } \\
\text { Mineiro }\end{array}$ & $\begin{array}{l}\text { Iniciou-se em } 2003 \text { as atividades, especializada na produção e comercialização de suínos, sendo } \\
\text { referência nacional na tecnologia e processamento de carnes. A cooperativa atua em três vertentes: } \\
\text { nutrição animal, frigorífico e lojas veterinária. Em 2014, faturou } 201 \text { milhões de reais. }\end{array}$ \\
\hline Baron & $\begin{array}{c}\text { Campos } \\
\text { Gerais }\end{array}$ & $\begin{array}{l}\text { Fundada em 1951, a cooperativa atua em cinco unidades de negócio: carne, leite, grãos, batata e } \\
\text { industrialização. A empresa possui unidades de beneficiamento de grãos, leite e batatas, fábricas de rações, } \\
\text { frigorífico de suínos e lojas comerciais. Em 2014, registrou 1,94 bilhões de faturamento e } 849 \text { cooperados. }\end{array}$ \\
\hline Bonanza & $\begin{array}{c}\text { Campos } \\
\text { Gerais }\end{array}$ & $\begin{array}{l}\text { A cooperativa teve início no ano de } 1925 \text {, no ramo leiteiro e produção de seus derivados. Atualmente, trabalha } \\
\text { com leite, suinocultura, fabricação de ração, desenvolvimento de sementes, assistência aos cooperados, postos } \\
\text { de combustíveis e lojas comerciais. Em } 2014 \text {, obteve um faturamento de } 1,56 \text { bilhões de reais. }\end{array}$ \\
\hline King Air & $\begin{array}{c}\text { Campos } \\
\text { Gerais }\end{array}$ & $\begin{array}{l}\text { Iniciou as atividades em 1960, com foco principal na produção de leite. Hoje, a cooperativa foca na } \\
\text { agricultura, abrange soja, milho, trigo, feijão e café, na produção de suínos e leite. A organização } \\
\text { possui lojas comerciais, postos de combustíveis, indústrias e desenvolve e comercializa sementes de } \\
\text { trigo e soja. Em 2014, faturou } 790 \text { milhões de reais. }\end{array}$ \\
\hline
\end{tabular}

Fonte: Dados da pesquisa

Organizações Rurais \& Agroindustriais, Lavras, v. 19, n. 1, p. 8-22, 2017 
A seguir o Quadro 2 retrata o perfil dos respondentes em cada cooperativa, com informações sobre cargo e tempo de atuação:

Antes de realizar as entrevistas, foi elaborado um roteiro com as questões agrupadas, sendo o primeiro grupo de questões para estabelecer o perfil dos respondentes e das cooperativas e; o segundo grupo para identificar as estratégias de crescimento adotadas por elas, seu grau de significância e impacto na estrutura, com questões específicas sobre cada tipo de estratégia de crescimento seguindo a visão de Wright, Kroll e Parnell (2000) e Barney e Hesterly (2007).

A partir da transcrição das entrevistas e da descrição dos dados coletados nos documentos, foi feita análise de conteúdo seguindo as três fases apontadas por Bardin (2006), que são: i) a pré-análise; ii) a exploração do material; e iii) o tratamento dos resultados, inferência e interpretação. $\mathrm{Na}$ fase da pré-análise, foi organizado o material, feita a leitura flutuante e escolha dos documentos. Na segunda fase, foi feita a exploração do material para definição das categorias de análise, o que serviu para confirmar a categorização pré-definida no segundo grupo de questões do roteiro de entrevistas, com foco nas estratégias de crescimento. Na terceira fase, foi feita a condensação e o destaque de informações que permitiram a compreensão dos principais elementos relacionados às estratégias adotadas pelas cooperativas e a comparação entre elas.

\section{APRESENTAÇÃO E ANÁLISE DOS REŞULTADOS}

Observa-se que, em geral, os entrevistados apresentaram tempo de empresa que possibilita conhecimento abrangente da organização: a média de tempo atuando nas cooperativas do Triângulo Mineiro foi de mais de 16 anos, com grandes dispersões em torno da média (desvio padrão de 10,27 anos), como a empresa Navajo, que o funcionário está na organização por 1,5 e a Meridian, em que o respondente trabalha há 40 anos. A média de tempo na cooperativa na região dos Campos Gerais foi de mais de 25 anos, com uma dispersão em torno da média de 4,78 anos. Os cargos ocupados estão relacionados com gestão, mesmo como o respondente da empresa Tupi, que possui o cargo de engenheiro agrônomo, mas possui funções estratégicas e de gestão.

Com base nas respostas dos entrevistados e nos documentos analisados, identificou-se que houve crescimento interno das cooperativas do Triângulo Mineiro nos últimos cinco anos, pelo aumento da comercialização, capacidade de produção e da força de trabalho. Esse aumento, segundo os respondentes, foi expressivo para a maioria das cooperativas, com exceção da empresa Jetprop, onde é apontado que não houve crescimento significativo. Nas cooperativas paranaenses, localizadas nos Campos Gerais, por meio das respostas dadas, também se identificou que houve crescimento interno de todas as três cooperativas nos últimos cinco anos, por meio do aumento da comercialização, da capacidade de produção e da força de trabalho.

QUADRO 2 - Tempo de Empresa e Cargo dos Respondentes

\begin{tabular}{|c|c|c|c|}
\hline Cooperativa & Região & Tempo de Empresa & Cargo \\
\hline Seneca - MG & Triângulo Mineiro & 22 anos. & Assessor de comunicação \\
\hline Saratoga - MG & Triângulo Mineiro & 15 anos & Gerente administrativo \\
\hline Matrix - MG & Triângulo Mineiro & 10 anos & Diretor superintendente \\
\hline Cherokee - MG & Triângulo Mineiro & 21 anos & Gerente financeiro. \\
\hline Meridian - MG & Triângulo Mineiro & 40 anos & Diretor superintendente \\
\hline Jetprop - MG & Triângulo Mineiro & 9 anos & Analista financeiro \\
\hline Tupi - MG & Triângulo Mineiro & 15 anos & Engenheiro agrônomo \\
\hline Corisco - MG & Triângulo Mineiro & 12 anos & Assessor de marketing \\
\hline Navajo - MG & Triângulo Mineiro & 1 ano e meio & Gerente comercial \\
\hline Baron - PR & Campos Gerais & 19 anos & Gerente de negócios \\
\hline Bonanza - PR & Campos Gerais & 30 anos & Gerente financeiro \\
\hline King Air - PR & Campos Gerais & 28 anos & Gerente industrial \\
\hline
\end{tabular}

Fonte: Dados da pesquisa 
O Quadro 3 apresenta os dados sobre a criação de unidades de negócio, considerando-se os últimos 5 anos, e qual a sua natureza e finalidade:

Nota-se que houve crescimento interno com a inserção em novos setores e atividades em seis cooperativas nos últimos cinco anos e estas novas unidades de negócio estão relacionadas com as atividades principais das cooperativas. Assim, realizaram integração vertical via crescimento interno conforme descrita por Wright, Kroll e Parnell (2000) e também por Barney e Hesterly (2007). Observa-se que há diversidade quanto ao tipo de unidades de negócios criadas, possuindo em maior quantidade a criação de unidades de natureza comercial, no caso das cooperativas mineiras. Já nas cooperativas paranaenses, identificou-se crescimento interno nas três cooperativas nos últimos cinco anos, com a inserção em novos setores e atividades e algumas novas unidades de negócio são semelhantes entre as cooperativas, como a abertura de frigorífico de suínos e indústria de leite nas três cooperativas e moinho de trigo por duas cooperativas. E que as novas unidades de negócio estão relacionadas com atividades principais das cooperativas, estando elas também executando integração vertical.

QUADRO 3 - Criação de Novas Unidades de Negócios - Últimos 5 Anos

\begin{tabular}{|c|c|c|}
\hline Cooperativa & Novas Unidades & Observação \\
\hline Seneca - MG & $\begin{array}{l}\text { Beneficiamento e } \\
\text { comercialização de soja e } \\
\text { milho. }\end{array}$ & $\begin{array}{l}\text { Criação de sistema de troca de insumos (por parte da cooperativa) por } \\
\text { produtos dos cooperados. } \\
\text { Desde a filiação com a cooperativa central, houve o ingresso em novos } \\
\text { segmentos, devido ter parado de trabalhar diretamente com o leite. }\end{array}$ \\
\hline Saratoga - MG & Loja comercial & $\begin{array}{l}\text { Criada esta unidade a fim de atender, especificamente, os cooperados nas suas } \\
\text { necessidades de aquisição de insumos e materiais }\end{array}$ \\
\hline Matrix - MG & Loja comercial & $\begin{array}{c}\text { Criada esta unidade a fim de atender, especificamente, os cooperados nas suas } \\
\text { necessidades de aquisição de insumos e materiais }\end{array}$ \\
\hline $\begin{array}{l}\text { Cherokee } \\
\text { - MG }\end{array}$ & Beneficiamento da produção & $\begin{array}{l}\text { Esta unidade foi criada para a prestação de serviço na recepção e } \\
\text { beneficiamento da produção dos cooperados. }\end{array}$ \\
\hline $\begin{array}{l}\text { Meridian } \\
\text { - MG }\end{array}$ & $\begin{array}{l}\text { Comercialização de } \\
\text { combustíveis }\end{array}$ & $\begin{array}{l}\text { Criada esta unidade a fim de atender, especificamente, os cooperados na } \\
\text { aquisição de combustíveis a fim de garantir a qualidade e estabilizar preços. }\end{array}$ \\
\hline Jetprop - MG & $\begin{array}{l}\text { Não houve a criação de novas } \\
\text { unidades de negócio. }\end{array}$ & \\
\hline Tupi - MG & $\begin{array}{c}\text { Não houve a criação de novas } \\
\text { unidades de negócio. }\end{array}$ & \\
\hline Corisco - MG & Loja comercial & $\begin{array}{c}\text { Criada esta unidade a fim de atender, especificamente, os cooperados nas suas } \\
\text { necessidades de aquisição de insumos e materiais }\end{array}$ \\
\hline Navajo - MG & $\begin{array}{c}\text { Não houve a criação de novas } \\
\text { unidades de negócio. }\end{array}$ & \\
\hline Baron - PR & $\begin{array}{l}\text { Beneficiamento e } \\
\text { comercialização de feijão } \\
\text { Industrialização de leite } \\
\text { Industrialização de carne suína }\end{array}$ & $\begin{array}{l}\text { Estas unidades foram criadas para atender as necessidades específicas de cada } \\
\text { tipo de produtor (de feijão, de leite e de suínos) no sentido de agregar valor } \\
\text { à produção (transformação e produtos derivados no caso do leite e suínos) e } \\
\text { comercialização. }\end{array}$ \\
\hline Bonanza - PR & $\begin{array}{l}\text { Beneficiamento de leite } \\
\text { Moinho de beneficiamento de } \\
\text { trigo Frigorífico de suínos. }\end{array}$ & $\begin{array}{l}\text { Estas unidades foram criadas para atender as necessidades específicas de cada } \\
\text { tipo de produtor (de leite, de trigo e de suínos) no sentido de agregar valor à } \\
\text { produção (transformação e produtos derivados) e comercialização. }\end{array}$ \\
\hline King Air - PR & $\begin{array}{l}\text { Comercialização de carne } \\
\text { suína no estado do São Paulo } \\
\text { Industrialização de suínos } \\
\text { Moinho de trigo } \\
\text { Industrialização do leite }\end{array}$ & $\begin{array}{c}\text { A unidade em São Paulo teve o objetivo de abrir novos mercados para a } \\
\text { comercialização da carne suína. As outras unidades foram criadas para atender } \\
\text { as necessidades específicas de cada tipo de produtor (de leite, de trigo e de } \\
\text { suínos) no sentido de agregar valor à produção (transformação e produtos } \\
\text { derivados) e comercialização. }\end{array}$ \\
\hline
\end{tabular}

Fonte: Dados da pesquisa

Organizações Rurais \& Agroindustriais, Lavras, v. 19, n. 1, p. 8-22, 2017 
Quanto ao uso de estratégias de aquisição do tipo integração vertical, ou seja, aquisição de outra empresa, ou cooperativa que pertence à mesma cadeia produtiva conforme Wright, Kroll, Parnell (2000) e Ross, Westerfield e Jaffe (2002), observou-se, dentre as cooperativas mineiras, que houve aquisição do tipo integração vertical nos últimos cinco anos somente na cooperativa Corisco, com a união de vários estágios de atividade regressivamente, com a produção de ração e suplementos e a distribuição de produtos. Identificou-se que houve aquisição do tipo integração vertical nas três cooperativas paranaenses nos últimos cinco anos, devido à união de estágios de atividades regressivamente. E que as três cooperativas realizaram o processo com o negócio leite e a suinocultura, e duas com o trigo. As três organizações ao utilizarem da integração vertical relacionaram o processo com as atividades principais da organização, e posicionaram a montante, na industrialização do produto primário.

Com relação à estratégia de fusão, não houve nenhuma por parte das cooperativas da região do Triângulo Mineiro e também dos Campos Gerais, pois não houve permuta de ação com empresas de mesmo tamanho.

Com relação à estratégia de integração horizontal via crescimento interno ou aquisição, não houve nenhum movimento nesse sentido nos últimos 5 anos, não foi realizada nenhuma aquisição de empresa ou cooperativa do mesmo setor na região do Triângulo Mineiro. Já nos Campos Gerais, a cooperativa King Air utilizou da aquisição para fins de integração horizontal, pois fez a incorporação de outra cooperativa da mesma linha de negócio. As outras duas cooperativas não utilizaram esta estratégia de crescimento.

Sobre iniciativas de parcerias e estratégias de cooperação nos últimos 5 anos, o Quadro 4 mostra as informações sobre cada uma das cooperativas pesquisadas, detalhando sobre o setor/área envolvido:

Identificou-se que sete cooperativas do Triângulo Mineiro iniciaram novas alianças estratégicas, com a união de esforços com outras organizações, com a finalidade de atingir objetivos estratégicos comuns, corroborando os argumentos de Aaker (2001). Observa-se que a aliança estratégica é utilizada principalmente com fornecedores, organizações financeiras e empresas que possuem patentes e são desenvolvedoras de sementes. Pode-se levantar alguns motivos para que as cooperativas utilizem de alianças estratégicas, como: a complexidade da atividade que tange a estratégia, acesso de recursos e competências do parceiro, acesso a mercados de produtos e geográficos, matéria-prima, superação de barreira e restrições, acesso ao capital de crédito de curto e longo prazos, de acordo com as afirmações feitas por Arruda e Arruda (1997) e Barney e Hesterly (2007).

Nos Campos Gerais, identificou-se que as três cooperativas utilizaram de alianças estratégicas nos últimos cinco anos, com a formação de parcerias para que duas ou mais empresas realizem projetos específicos ou cooperem em determinadas áreas de negócio. Observa-se que as três empresas utilizaram da intercooperação, em seu segundo estágio, deixando a administração da unidade de negócio para o maior investidor o que ratifica Barroso et al (2007) no que diz respeito aos processos que ocorrem no estágio inicial das estratégias de intercooperação. Houve parcerias estratégicas com a cooperação no desenvolvimento de sementes pela cooperativa Bonanza. Pode-se levantar alguns motivos pelos quais as cooperativas iniciaram novas alianças estratégicas: a complexidade da atividade que tange a estratégia, acesso de recursos e competências do parceiro, acesso a mercados de produtos e geográficos, conhecimento sobre mercados, matéria-prima, superação de barreira e restrições e acesso ao capital de crédito de curto e longo prazos, também corroborando Arruda e Arruda (1997).

\section{ANÁLISE COMPARADA DAS COOPERATIVAS POR REGIÕES}

As cooperativas do Triângulo Mineiro e da região dos Campos Gerais, apesar das distâncias que as separam, de variáveis históricas e regionais, apresentaram um comportamento estratégico muito próximo em relação às ações de crescimento nos últimos cinco anos.

As cooperativas das duas regiões aumentaram, significativamente, a comercialização, a capacidade de produção e a força de trabalho. Referente ao crescimento interno com a inserção em outros negócios, as cooperativas do Triângulo Mineiro utilizaram mais intensamente estratégias de crescimento interno do que de aquisição do tipo integração vertical, dentro das cadeias produtivas que já operam. As cooperativas paranaenses usaram a estratégia do crescimento interno aliada à intercooperação, presente em todo seu crescimento nos últimos cinco anos, com a criação de unidades de negócio de natureza industrial. As cooperativas do Triângulo Mineiro, proporcionalmente, exploraram menos esta estratégia e diversificaram, principalmente, criando unidades comerciais. Os possíveis motivos que levaram as cooperativas a utilizar a estratégia de integração vertical são: custos de transação, ordem técnica, eficiência econômica e competição conforme razões citadas por Britto (2002). Percebe-se que todos os processos de integração vertical foram utilizados na atividade principal das cooperativas. 
QUADRO 4 - Estratégias de Cooperação

\begin{tabular}{|c|c|}
\hline Cooperativas & Respostas \\
\hline Seneca - MG & $\begin{array}{l}\text { Sim, com fornecedores de insumos, empresas como Yara e Fertigran, organizações que trabalham com a } \\
\text { comercialização de produtos no mercado futuro, como a Syngenta, entre outros. As parcerias estratégicas } \\
\text { permeiam todos os setores da cooperativa. }\end{array}$ \\
\hline Saratoga - MG & $\begin{array}{c}\text { Sim, a cooperativa iniciou parcerias estratégicas com várias empresas, e em todas as áreas da organização. Um } \\
\text { exemplo é na área financeira, com o CICOOB, uma cooperativa de crédito. }\end{array}$ \\
\hline Matrix - MG & Não, devido as propostas que foram feitas não apresentaram nenhuma vantagem para a empresa. \\
\hline Cherokee - MG & $\begin{array}{l}\text { Sim, com empresas que desenvolvem novas variedades de semente de soja e trigo, tanto fundações } \\
\text { governamentais e sem fins lucrativos, como a Embrapa, quanto organizações privadas. Envolve } \\
\text { principalmente o setor de pesquisa e desenvolvimento. }\end{array}$ \\
\hline Meridian - MG & $\begin{array}{c}\text { Sim, nos últimos cinco anos iniciou-se um consórcio de cooperativas. A parceria estratégica foi feita com } \\
\text { várias cooperativas do agronegócio. Envolve a área de compra da organização. }\end{array}$ \\
\hline Jetprop - MG & Não. \\
\hline Tupi - MG & $\begin{array}{l}\text { Sim, realizou parcerias estratégicas referente a representação da marca da cooperativa, para a comercialização } \\
\text { dos produtos produzidos por ela. Envolve os departamentos de comercialização. }\end{array}$ \\
\hline Corisco - MG & $\begin{array}{l}\text { Sim, a cooperativa realizou parcerias estratégicas, com cooperativas de crédito e fornecedores. Envolve } \\
\text { principalmente os departamentos de compra e financeiro. }\end{array}$ \\
\hline Navajo - MG & $\begin{array}{l}\text { Sim, nos últimos cinco anos houve parcerias estratégicas com fornecedores, laboratórios, universidades } \\
\text { e escolas. Envolve todos os setores da cooperativa, porém principalmente no de compra, pesquisa e } \\
\text { desenvolvimento e produção. }\end{array}$ \\
\hline Baron - PR & $\begin{array}{l}\text { Sim, com cooperativas do agronegócio principalmente, com a intercooperação. Envolve os setores de } \\
\text { produção, mais especificamente a industrialização dos produtos primários, leite, suinocultura e trigo. }\end{array}$ \\
\hline Bonanza - PR & $\begin{array}{l}\text { Sim, houve a intercooperação com outras cooperativas, que envolve os setores de produção, mais } \\
\text { especificamente a industrialização de produtos primários, e a parceria com empresas de desenvolvimento de } \\
\text { sementes, como Monsanto, Syngenta e Brasmax, que envolve setores de pesquisa e desenvolvimento. }\end{array}$ \\
\hline King Air - PR & $\begin{array}{l}\text { Sim, houve a criação de parcerias estratégicas com outras cooperativas, chamado de intercooperação, nos } \\
\text { setores de carne, trigo e leite, todos eles relacionado a industrialização. }\end{array}$ \\
\hline
\end{tabular}

Fonte: Dados da pesquisa

Nas duas regiões as cooperativas iniciaram alianças estratégicas nos últimos cinco anos, pelo motivo citado por Aaker (2001) da união de esforços das organizações com a finalidade de alcançar um objetivo estratégico comum. Percebe-se que a aliança estratégica foi a principal forma de estratégia cooperativa utilizada nos últimos cinco anos nas duas regiões e identificou-se que há diferença na utilização da estratégia nas duas regiões. $\mathrm{Na}$ região dos Campos Gerais, a estratégia foi utilizada no formato de intercooperação, em seu segundo estágio, para a criação de unidades industriais e parceria com empresas desenvolvedores de semente. No Triângulo Mineiro, utilizou-se de aliança estratégica com maior diversificação, os principais foram: fornecedores, empresas de desenvolvimento de semente, representação de marcas e consórcio entre cooperativas, esta última constitui de uma forma de intercooperação de segundo estágio. Pode-se levantar os motivos do uso de alianças estratégicas como: complexidade da atividade que tange a estratégia, acesso de recursos e competências do parceiro, acesso a mercados de produtos e geográficos, conhecimento sobre mercado, matéria-prima, superação de barreira e restrições e acesso ao capital de crédito de curto e longo prazo conforme tratado por Arruda e Arruda (1997). O Quadro 5 representa o resumo comparativo entre as cooperativas por regiões.

Ao usar a taxonomia de Miles e Snow (1978) para classificar o comportamento estratégico competitivo das cooperativas com relação ao seu ambiente, conforme mostrado na última linha do quadro anterior, é possível afirmar que as cooperativas de ambas as regiões conseguiram se adaptar ao seu meio ambiente compreendido no ciclo adaptativo. Especificamente, as cooperativas da região do Triângulo Mineiro apresentaram características da estratégia analítica, pois dependem e

Organizações Rurais \& Agroindustriais, Lavras, v. 19, n. 1, p. 8-22, 2017 
QUADRO 5 - Resumo comparativo entre as cooperativas por regiões

\begin{tabular}{|c|c|c|}
\hline Elemento Analisado & Região dos Campos Gerais & Região do Triângulo Mineiro \\
\hline $\begin{array}{c}\text { Capacidade Produtiva e Força de } \\
\text { Trabalho }\end{array}$ & Aumento significativo & Aumento significativo \\
\hline $\begin{array}{l}\text { Crescimento Interno Com A } \\
\text { Inserção Em Outros Negócios }\end{array}$ & $\begin{array}{c}\text { Fizeram uso da estratégia de } \\
\text { crescimento interno aliada à } \\
\text { intercooperação, presente em todo seu } \\
\text { crescimento nos últimos cinco anos, } \\
\text { com a criação de unidades de negócio } \\
\text { de natureza industrial }\end{array}$ & $\begin{array}{c}\text { Utilizaram mais intensamente estratégias de } \\
\text { crescimento interno do que de aquisição do tipo } \\
\text { integração vertical, dentro das cadeias produtivas } \\
\text { que já operam. }\end{array}$ \\
\hline Uso De Alianças Estratégicas & $\begin{array}{l}\text { Utilizaram o formato de } \\
\text { intercooperação, em seu segundo } \\
\text { estágio, para a criação de unidades } \\
\text { industriais e parceria com empresas } \\
\text { desenvolvedores de semente. }\end{array}$ & $\begin{array}{l}\text { Proporcionalmente, exploraram menos a } \\
\text { estratégia de intercooperação e diversificaram, } \\
\text { principalmente, criando unidades comerciais. } \\
\text { Elas fizeram uso de aliança estratégica com } \\
\text { maior diversificação, os principais foram: } \\
\text { fornecedores, empresas de desenvolvimento de } \\
\text { semente, representação de marcas e consórcio } \\
\text { entre cooperativas, esta última constitui de uma } \\
\text { forma de intercooperação de segundo estágio. }\end{array}$ \\
\hline $\begin{array}{l}\text { Comportamento Estratégico } \\
\text { Competitivo das Cooperativas }\end{array}$ & $\begin{array}{l}\text { Apresentaram características de } \\
\text { estratégia prospectora, onde a busca } \\
\text { por novos mercados e produtos é } \\
\text { intensa e leva-as à uma dinâmica } \\
\text { de diversificação mais acelerada } \\
\text { e sustentada pela estrutura e pela } \\
\text { intercooperação das cooperativas. }\end{array}$ & $\begin{array}{c}\text { Elas presentaram características da estratégia } \\
\text { analítica, pois dependem e estão estruturadas } \\
\text { com base em uma atividade ou cadeia produtiva } \\
\text { principal, mais estável com algumas unidades } \\
\text { de negócios mais dinâmicas onde se permitem } \\
\text { maiores riscos. }\end{array}$ \\
\hline
\end{tabular}

Fonte: Análise dos Dados da pesquisa

estão estruturadas com base em uma atividade ou cadeia produtiva principal, mais estável com algumas unidades de negócios mais dinâmicas onde se permitem maiores riscos. Já as cooperativas da região dos Campos Gerais foram identificadas como apresentando estratégia prospectora, onde a busca por novos mercados e produtos é intensa e leva-as a uma dinâmica de diversificação mais acelerada e sustentada pela estrutura e pela intercooperação das cooperativas.

\section{CONSIDERAÇÕES FINAIS}

A cooperativa é uma forma eficiente de organização difundida no Brasil, que possui importância econômica e social e as cooperativas agrícolas e agropecuárias correspondem a mais de $50 \%$ do total de cooperativas do país (OCB, 2013). Este tipo organizacional possibilita o aumento da renda dos associados e desenvolvimento econômico na região, principalmente de produtores rurais. Assim, esta pesquisa buscou analisar quais foram as estratégias de crescimento utilizadas por cooperativas agrícolas e agropecuárias do Triângulo Mineiro/ MG e dos Campos Gerais/PR, duas regiões de reconhecida importância para o agronegócio e para o cooperativismo.

Nas duas regiões, as cooperativas adotaram mais intensamente a estratégia de crescimento interno no próprio negócio e de forma menos acentuada, o crescimento via aquisição, ambas as estratégias do tipo integração vertical. Houve também iniciativas de estratégias de cooperação e é nesse ponto que reside uma grande diferença entre as regiões: as alianças estratégicas no Triângulo Mineiro caracterizaram-se por parcerias com fornecedores e com instituições financeiras. Já nos Campos Gerais, houve estratégia de intercooperação o que possibilitou a divisão dos riscos, custos e os benefícios de adentrarem em um negócio.

Utilizando a taxonomia de Miles e Snow (1978) aliada ao fato de as cooperativas do Triângulo Mineiro e dos Campos Gerais apresentaram similaridades em relação às estratégias de crescimento adotadas, foi possível a comparação entre as regiões. Portanto, conclui-se que as cooperativas da região do Triângulo 
Mineiro e dos Campos Gerais utilizaram a adaptação estratégica ao ambiente denominada de ciclo adaptativo, que visa solucionar os problemas de ordem empresarial, tecnológica e administrativa, mas com intensidade maior, as cooperativas dos Campos Gerais adotaram estratégias de crescimento e com maior complexidade do que as cooperativas do Triângulo Mineiro.

Como contribuição teórica, este estudo buscou unir a perspectiva mais abrangente de Miles e Snow (1978) para classificar o comportamento estratégico das cooperativas com uma análise mais específica de suas estratégias de crescimento, apoiando-se em Wright, Kroll e Parnell (2000). Assim, foi possível compreender como os comportamentos estratégicos do tipo prospector e analítico foram evidenciados na forma de estratégias de criação de novas unidades de negócios, aquisição vertical e cooperação. Já como contribuição prática, este estudo auxilia na compreensão da transformação da estrutura das cooperativas e seus efeitos no que diz respeito às estratégias adotadas para o crescimento perante o mercado $\mathrm{e}$, principalmente, para o atendimento das demandas de seus cooperados, bem demonstrado pela segmentação das unidades de negócios que estão atreladas às atividades de grupos de produtores cooperados.

Como limitações deste estudo, considera-se que mesmo utilizando-se, de forma combinada, o modelo de Miles e Snow (1978) com a análise das estratégias de crescimento de Wright, Kroll e Parnell (2000), entende-se que muitos aspectos e elementos das estratégias e dos processos de gestão das cooperativas não foram alcançados, como por exemplo, a influência da forma colegiada de decisão, característica própria das cooperativas. Outra limitação foi o número reduzido de entrevistas, em que se pese que os entrevistados foram todos os principais gestores das cooperativas com muitos anos de atuação neste setor, teria sido enriquecedor ter a oportunidade de conhecer outros pontos de vista como dos cooperados e fornecedores.

Propõe-se, como estudos futuros, analisar de maneira mais pormenorizada a trajetória de cada cooperativa, com a utilização de outros modelos/perspectivas, não somente o de Miles e Snow (1978) e estratégias de crescimento de Wright, Kroll e Parnell (2000), para identificar e analisar tanto as estratégias como também recursos e competências específicos de cada contexto organizacional. Outra sugestão seria analisar o motivo de as cooperativas do Triângulo Mineiro não realizarem intercooperação e os fatores que influenciam as cooperativas da região dos Campos Gerais a utilizarem desta estratégia.

\section{REFERÊNCIAS}

AAKER, D. A. Administração estratégica de mercado. Porto Alegre: Bookman, 2001.

ANACLETO, A. Flowers supply chain in Paraná Coast - Brazil: an application of Miles and Snow taxonomy. Revista Capital Científico - Eletrônica, v. 14, n. 1, p. 10-25, 2016.

ARRUDA, M. C. C.; ARRUDA, M. L. de. Alianças estratégicas internacionais: formação e estruturação em indústrias manufatureiras. Revista de Administração de Empresas, v. 37, n. 4, p. 28-37, 1997.

BAHLS, S. N.; MARTINS, T. S.; KATO, H. T. A relação entre a tipologia estratégica de Miles e Snow e os grupos estratégicos do setor hoteleiro do Estado do Paraná. Caderno Virtual de Turismo, v. 14, n. 3, p. 234-249, 2014.

BARNEY, J. B.; HESTERLY, W. S. Administração estratégica e vantagem competitiva. São Paulo: Pearson Prentice Hall, 2007.

BARROSO, M.F. G.; TORGGLER, S.P.; BIALOSKORSKI NETO, S.; TRINDADE, M. T.; RAIMUNDO, T. D. An essay about operational integrative strategies in São Paulo dairy cooperatives. In: VI International PENSA Conference, 2007, Ribeirão Preto. Proceeding of the 6th International PENSA Conference, 2007. Anais...

BARDIN, L. Análise de conteúdo. Lisboa: Edições 70, 2006.

BATALHA, M. O.; SILVA, A. L. Sistemas Agroindustriais: definições e correntes metodológicas. In: BATALHA, M. O. (Coord.). Gestão agroindustrial: GEPAI - grupo de estudos e pesquisas agroindustriais. 3 ed. $7^{\text {a }}$ reimpressão. São Paulo: Atlas, 2013.

BIALOSKORSKI NETO, S.; GOMES, C. B. Um ensaio sobre os desafios da intercooperação entre cooperativas agropecuárias no Brasil. In: I Encontro Brasileiro de Pesquisadores em Cooperativismo (EBPC), 2010, Brasília. Anais...

BIALOSKORSKI NETO, S. Agronegócio cooperativo. IN: BATALHA, M. O. (Coord.). Gestão agroindustrial: GEPAI - grupo de estudos e pesquisas agroindustriais. 3 ed. $7^{\mathrm{a}}$ reimpressão. São Paulo: Atlas, 2013. 
BRITTO, J. Diversificação, competências e coerência produtiva. In: KUPFER, D.; HASENCLEVER, L. (Org.). Economia industrial: fundamentos teóricos e práticas no Brasil. Rio de Janeiro: Campus, 2002.

BOWMAN, E. H.; HELFAT, C. E. Does corporate strategy matter? Strategic Management Journal, v. 22, p. 1-23, 2001 .

CHAKRABARTI, A. Organizational adaptation in an economic shock: the role of growth reconfiguration. Strategic Management Journal, v. 36, p. 1717-1738, 2015.

CRÚZIO, H. de O. Organização e administração de cooperativas. Revista de Administração Pública, Rio de Janeiro, v. 33, p. 39-58, mar./jun. 1999.

DESARBO, W.; BENEDETTO, C. A; SONG, M.; SINHA, I. Revisiting the Miles and Snow strategic framework: uncovering interrelationships between strategic types, capabilities, environmental uncertainty, and firm performance. Strategic Management Journal, Chichester, v. 26, n.1, p. 47-74, Jan. 2005.

FARIAS FILHO, M. C. ARRUDA FILHO, E. J. M. Planejamento da pesquisa científica. São Paulo: Atlas, 2013.

GALLAS, J. C.; CANCELLIER, L. P. L.; VARGAS, S. M. L.; ROSSETTO, C. R. Comportamento estratégico no setor de beleza e estética baseado na tipologia de Miles e Snow. Revista Organizações em Contexto, v. 11, n. 22, p. 119-141, 2015.

GIMENEZ, F. Escolhas estratégicas e estilo cognitive: Um estudo com pequenas empresas. Revista de Administração Contemporânea, Curitiba, v. 2, n. 1, p. 27-45, jan./abr. 1998.

GIMENES, R. M. T.; GIMENES, F. M. P. Agronegócio cooperativo: a transição e os desafios da competitividade. Revista do Desenvolvimento Regional, Santa Cruz do Sul, v. 12, n. 2, p. 92-108, mai./ago. 2007.

GIMENEZ, F. A. P.; PELISSON, C.; KRUGER, E. G. S.; HAYASHI JUNIOR, P. Estratégia em pequenas empresas: uma aplicação do modelo de Miles e Snow. Revista de Administração Contemporânea, Curitiba, v. 3, n. 2, p. 53-74, Aug. 1999.
GHEMAWAT, P.; RIVKIN, J. W. Escolhendo o escopo corporativo. IN: GHEMAWAT, P. A estratégia e o cenário dos negócios. $3^{\mathrm{a}}$ ed. Porto Alegre: Bookman, 2012.

GITMAN, L. J. Princípios de Administração Financeira. 7. ed. São Paulo: Habra, 2002.

HITT, M. E.; IRELAND, D. R. Relationships among corporate level distinctive competencies, diversification strategy, corporate structure and performance. Journal of Managemmt Studies, v. 23, n.4, 1986.

HOPEWELL, K. The transformation of state-business relation in a emerging economy: The case of Brazilian Agribusiness. Critical Perspectives on International Business, v. 10, n. 4, p. 291-309, 2014.

HOSKISSON, R. E.; HITT, M. A.; IRELAND, R. D.; HARRISON, J. S. Estratégia Competitiva. 2. ed. São Paulo: Cengage, 2010.

KLEINBAUM, A. M.; STUART, T. E. Inside the black box of the corporate staff: social networks and the implementation of corporate strategy. Strategic Management Journal, v. 35, p. 24-47, 2014.

LOPES H. E. G.; MOURA T. N.; OLIVEIRA C. C.G. Os perfis estratégicos no Brasil: um estudo dos agentes franqueados dos correios a partir da tipologia de Miles e Snow. Revista Brasileira de Gestão de Negócios, São Paulo, v. 12, n. 37, p. 388- 404, out./dez. 2010.

MILES, R. E.; SNOW, C. C. Organizational Strategy, Structure, and Process. Nova York: McGraw-Hill, 1978.

MINTZBERG, H.; AHLSTRAND, B.; LAMPEL, J. Safári de Estratégia: Um roteiro pela selva do planejamento estratégico. 2. ed. Porto Alegre: Bookman, 2010.

ORGA NIZAÇÃ O DAS COOPERATIVAS BRASILEIRAS. Relatório de Atividades OCB 2013. Brasília, 2013. Disponível em: < http://relatorioocb2013. brasilcooperativo.coop.br/wp-content/uploads/2014/04/ relatorio_gestao_OCB_2013.pdf $>$. Acesso em: 27/03/2015.

ORGANIZAÇÃO DAS COOPERATIVAS DO ESTADO DE MINAS GERAIS. Anuário de Informações Econômicas e Sociais do Cooperativismo Mineiro 2014. Belo Horizonte: EGL, 2014. 
ORGANIZAÇÃO DAS COOPERATIVAS DO ESTADO DO PARANÁ. Cooperativismo paranaense: desenvolvimento sustentável no campo e na cidade. Curitiba, 2013. Disponível em: <http://www. paranacooperativo.coop.br/ppc/index.php/sistema-ocep ar/2011-12-05-11-29-42/2011-12-05-11-42-54>. Acesso em: 17/06/2015.

PORTER, M. E. Estratégia competitiva: Técnicas para Análise de Indústrias e da Concorrência. 7. ed. Rio de Janeiro: Elsevier, 2005.

ROSS, S. A.; WESTERFIELD, R. W.; JAFFE, J. F. Administração Financeira: Corporate Finance. 2. ed. São Paulo: Atlas, 2002.

SANTOS, A. R dos. Metodologia científica. 7. ed. Rio de Janeiro: DP\&A, 2004.

SILVA, E. S.; McINTYRE, J. P.; PIRES, M. L. S. Panorama do Cooperativismo Brasileiro: História, Cenários e Tendências. Unircoop, v.1, n. 2, p. 75-102. 2003.

VASCONCELOS, F. Safári de estratégia, questões bizantinas e a síndrome do ornitorrinco: uma análise empírica dos impactos da diversidade teórica em estratégia empresarial sobre a prática dos processos de tomada de decisão estratégica. IN: Encontro Nacional Dos Programas De Pós-Graduação Em Administração, Campinas, 2001. Anais...

VIEIRA, V.; MACHADO, R. K.; BREY, N. K.; ROSSETTO, C. R. Evidências das pesquisas que abordam a tipologia de Miles e Snow no Brasil. Revista Ibero-Americana de Estratégia, v. 11, n. 2, p. 70-90, 2012.

VILELA, N. J.; MACEDO, M. M. C. Fluxo de poder no agronegócio: o caso das hortaliças. Revista da Associação Brasileira de Horticultura, Brasília, v. 18, n. 2, p. 88-94, jul. 2000.

WRIGHT, P.; KROLL, M. J.; PARNELL, J. Administração Estratégica. 1. ed. São Paulo: Atlas, 2000.

YIN, R. K.. Estudo de caso: planejamento e métodos. 5. ed. Porto Alegre: Bookman, 2015.

ZAJAC, E.; SHORTEEL, S. Changing generic strategies: likelihood, direction, and performance implications. Strategic Management Journal, Chichester, v. 10, n. 3, p. $413-430,1989$. 